\title{
The Identity of Jim in "The Adventures of Huckleberry Finn" from the Postcolonial Perspective
}

\author{
Yujin Li \\ International Institute of Chinese Studies \\ Beijing Foreign Studies University \\ Beijing, China
}

\begin{abstract}
The post-colonial theory opposes the essentialism of the nation and identity. It advocates the concept of "hybridity" and uses it as a strategy to resist the discourse of colonialism. This article, through a textual analysis of the identification problem of slave Jim in Mark Twain's "The Adventures of Huckleberry Finn", points out that although Jim's identity is forced on himself by social system (slavery) and cultural tradition (racism), Jim in a difficult situation, like the post-colonial theory imagined, actively use the hybrid strategy to strike back racist system. The pursuit of identity is not only a sarcasm and complaint against the racial system, but also shows people's identity confusion in modern society.
\end{abstract}

Keywords-postcolonial criticism; Mark Twain; "The Adventures of Huckleberry Finn"; identity

\section{INTRODUCTION}

"Post-colonial theory" generally refers to the reflection and criticism of the imperialist discourse of European and American countries through the analysis of colonial literature and post-colonial literature. Cultural identity research has always been one of the most important issues for post-colonial critics. Cultural identity involves the issues of "who am I", " what I identify with" and so on. Post-colonial critics do not regard cultural identity as rigid, absolute, and immutable. For example, Said believes, "Human identity is not formed naturally and stable, but is artificially constructed" [1]. Bhabha believes that the past colonized people and immigrants in today's multicultural society have no other choice but to live in a world "between cultures", creating their own identity in a contradictory and conflicting tradition. They are both "this and that" at the same time, and lived in the turbulent and painful process of cultural transformation. In Bhabha's opinion, this hybridity of identities is not an only choice but also a strategy and a method by which colonial and post-colonial subjects used to resist the colonial discourse, elucidate their own rights, and send out their voice as a disadvantaged group.[2] Salve Jim's Mark experience in Twain's "The Adventures of Huckleberry Finn" deeply embodied this strategy and method.

\section{SALVE JIM'S IDENTITY PROCESS}

In the middle and late 19th century, American capitalism developed rapidly. Soon the economic crisis broke out in 1873 , and there was a recurring trend. The American ruling class, in order to shift the contradictions, deliberately blamed the ethnic minorities for the increase in the unemployment rate of workers caused by the economic crisis and the reduction of the living standards of the residents, spread racial prejudice, implemented ethnic oppression, and incidents of persecuting slaves and killing slaves has often happen[3]. Jim lived in the southern part of United States in the late nineteenth century, and the Slavery in the south was the birthplace of American social racism, its "former slaves" are now the subject to racial discrimination in their own country. The American black culture was deprived and destroyed, and they are still plagued by slavery ghosts in daily life. At the turn of the century, the southern United States still separated people's living environment by the principle of race, such environment does not allow the slightest ambiguity in black and white issues. This is also the identity crisis faced by thousands of ethnic minorities living in American society [4]. Before the outbreak of the Civil War, the southern society, especially the upper class, which imposed the slavery system, did not regard the slaves as humans, but only as a living tool without emotion that could be driven.

Like other slaves, the black Jim did not receive any socalled "civilization" education from the white people, and also never to be "enlightened". Before he fled with Huck, he was willing to be a servant without social status. Jim did not even have a surname, his name was only a mockery of the society at that time, and "Jim" was a black nickname in the context of American culture at that time. The thought of feudal superstition in Jim's mind is deeply rooted Jim appeared in the first part of the second chapter, Tom teased him and put his hat on the tree above his head, when Jim awoke, he thought he was "bewitched by a witch"; He told other slaves that the five cents discovered in the kitchen was the amulets the devil had given him, he also said that the demon witches rode him around the world; Jim appeared in the fourth chapter to ask for shrine for the second time, this time his words were superstitious again, superstition is not believable, even though Jim was accurate, all he said was verified one by one later; From the eighth chapter, Huck and Jim formally began their journey and Jim's words were also increased. But like the previous chapters, Jim's words began as superstition. When they met, he told Huck about how he escaped and what difficulties he had encountered on the island, Jim noticed some signs and told Huck some of the many signs he knew. For example, he told Huck that his hairy arm and chest showed that he would make a fortune one day. In the days that 
followed, Jim told Huck that when he saw the bird fly away, he predicted that there was heavy rain, and playing with the snakeskin would bring bad things... Jim's superstition was the same as what he counted, they all came into reality one by one.[5] Looking at the full text, superstition is full of Jim's mind, regardless of the difficulties he and Huck will encounter, he can justify himself from the view of superstition. However, the realization of superstition is not a ridiculous coincidence; it is the life experiences that Jim has accumulated as a black and after year-round production labor.

The black Jim is in the lower layer of society and he has absolutely no right to speak. This is particularly evident in Chapter 14, "Solomon is smart or not". They discussed the King Solomon, both of whom are familiar with it. Jim feels that Solomon is not smart because Solomon didn't know that splitting the child in half can not answer the question of which the child belongs to. When Huck couldn't find a reason to refute Jim's words, he said that Jim was unreasonable," It was useless to talk to him - like to teach a black man something, there is no way to do that." [5] We see Huck is consciously felt superior to Jim. Huck accepted white people education and had a "civilized" face, he can not understand Jim's reasoning, although he knew that Jim had practical common sense, Huck still insisted on the standards of his surrounding environment he could not let the right to speak fall into black hands [6]. Huck's thought that white people is superior to black people has directly influenced his opinions on Jim, but Jim did not have any meaning to blame Huck. Instead, he treated him as his best friend and took care of him when they were drifting on the big river; When Tom was shot and wounded, he ignored his own safety and stayed in a dangerous area to assist doctors to rescue him. Jim deeply missed his wife and daughter, when he mentioned that he had slapped his four-year-old daughter in an angry manner, he said that he would never forgive himself for treating a poor deaf child so cruelly [5] ... Jim is simple, kind, honest, sincere, with rich spiritual world and the excellent quality of self-sacrifice, but the white people do not value him for his outstanding qualities, they judge him only from the perspective of skin color and believe he was in a low status, so he was meant to be white people's servant. Under slavery system, black people were merely white people's property. Not only they do not have white people's social status, they can not be counted as a person. Obviously, the feudal consciousness of colonialism is deeply rooted in people's hearts. The identity of black people affected his behavior and also affected the world in his eyes. At that time, Jim was sympathetic but overly passive and somewhat resigned, he valued his value in dollars, it can be seen that the racism prejudices prevailing in the southern United States have already established a white-dominated, white-oriented, dollaroriented illusory, fake ideology in the hearts of enslaved blacks. Moreover, such right and wrong judgment based on racial differences will inevitably distort normal humanity development and distort the hearts of those oppressed such like Jim [7].

Although Jim believes in superstition and submissiveness, there are all kinds of deficiencies on him, but when he learns that Miss Watson will sell him for $\$ 800$, he bravely escaped and want to go to the Free State and waits until he makes enough money, he will save his wife and children. This is Jim's first blur self-identity. He doesn't want to be a slave anymore, he wants to be treated like other white people and live happily with his family. The awakening of Jim's consciousness as an equal "person" reflects the pursuit and aspiration of black people for freedom and for the life of the real "human." He no longer wants to be the "other", an oppressed person on the edge of society. In order to find his identity, Jim fled with Huck. Jim's dilemma is that he has black blood, but he can take initiative to find his identity, resist white words, and ultimately free himself.

In the last few chapters of the third part, after escaping, Jim truly completed his identity. He is no longer the foil of Tom's stupid adventure game. He is a person himself and has his own way of behaving, which is consistent with the behavior he established when he ventured with Huck on the river in the first few chapters of the book. He not only cares about the wounded Tom even willing to sacrifice his freedom, but also has a strong character to ignore Tom's opposition. There is no one - at least between Huck and Jim - dominate Tom like that. Until then, Jim completely regained the right to speak - from the upper whites, not only from Tom, but also from Aunt Sarah, Silas, and doctor, etc., even recaptured the disclosure right from the lower white Huck [6]. Huck's understanding of Jim is a journey of realization, a journey of learning, and a journey of life. Huck accepted the traditional notion that blacks were born cheaper than whites, and the fate of blacks was at the mercy of their white owners. He was taught that slavery is good and right, helping a chased slave to escape is going to "go to hell". Huck's heart was full of contradictions, on one side was the sincere feelings of Jim and the other side was the secular punishment of the society. But in the end Huck set aside prejudice and discrimination and grew into a person with a sound mind. He believes Jim was a sentimental person who is righteous, can think independently, and live on an equal footing with others.

\section{CONCLUSION}

Mark Twain let Jim took the whole heavy cross of racial discrimination and eventually allowed him to be free. Through such a comedic literary treatment, Mark Twain expressed his fighting attitude towards irrational phenomena such as racism, and gives sympathy and support to the persecuted black slaves. Identity problems often plague Mark Twain's characters, many of them lived in extremely sinister environments, they not only exposed to the danger of losing their external physical form, but also highly likely to lose their basic self-consciousness. But Jim did not like this, his escape, he tried to establish his own way of doing things, he was finally able to disregard Tom's opposition are all the expression of his efforts to pursue his identity. This process of pursuing identity is not only a revelation of the racial system, but it also coincides with the tragedy of the modern people who are behind bars. Although Mark Twain has no way to trace the roots of the darkness and humanity extinction of Western society, it is even less likely to indicate a way out for the plight of modern people. However, with his outstanding artistic skills and profound ideological connotations, he provides us with an opportunity to examine Western modern culture, and also provides a valuable key to 
understanding human nature. The problems revealed by Mark Twain's works are undoubtedly inseparable from the development of the modern Western society, we are still plagued by issues such as cultural identity during nowadays where wave of globalization sweeping the entire world. Mark Twain is recognized as a master of 19th century world literature, his vision is advanced and his thoughts are profound. Although when Mark Twain first started on the road to literature, he became famous by writing humorous short stories, but his keen eyes, benevolence heart, his cynical sense of grief, and his courage to demand social fairness are extremely rare. It is precisely because of this that we see the eulogies of the universal value of human beings in the "Adventure of Huckleberry Finn". Starting from such an ideological basis, Mark Twain will surely stand by Jim and other persecuted people and fight for their injustice and ask for justice. This is one of the reasons why this realist master still has many researchers in today's post-modern and post-colonial context. Today we read Marc Twain's novels again from the theoretical perspective of cultural identity, it is clear that some of the topics that today's cultural researchers are passionate tot discuss have already been performed profoundly in the works he wrote more than a hundred years ago.

Furthermore, behind the issue of identity, post-colonial theory advocates cultural diversity and difference. Cultural diversity is a basic feature of human society and also is the driving force for the development of human civilization. Any cultural hegemony that attempts to put one culture above another culture is wrong. Civilization cannot be closed. On one hand, it undergoes self-renewal; on the other hand, it is also influenced by external civilization. Therefore, the integration of culture is also an inevitable trend [8]. In the process of integration, different ethnic cultures should conduct equal dialogue under the premise of mutual respect and conduct cultural exchanges in an atmosphere of equality and openness.

\section{REFERENCES}

[1] Said,Edward.Afterword.Orientalism.Trans.Wang Yugen.Beijing:TheJoin tPublishingCompanyLtd.,1999,p427.

[2] Bhabha,Homi."Unpacking My Library...Again."The Postcolonial Question:CommonSkies,DividedHorizons.Eds.IainChambersandLindaC urti.London:Routledge, 1996.

[3] Zhang Hong. The rainbow across the Pacific Ocean: American Writers and Chinese Culture [M]. Ningxia People's Publishing Company, 2002, P.43.

[4] Xian Anfeng. Whiteskin, whiteface mask: The identity stalemate of the hero Jos Cresmer in The Light of August[J]. Foreign Literature Studies, 2004(4):44-49.

[5] Mark Twain. The Adventures of Huckleberry Finn [M]. Foreign Language Teaching and Research Press, 1992.

[6] Li Yuan, Guo Lei. The Return of Discourse Power: The Postcolonialism in The Adventures of Huckleberry Finn[J]. China's Extracurricular Education: Theory, 2009(1): 75-76 .

[7] $\mathrm{Hu}$ Songbo. A Post-colonial Interpretation of "The Adventures of Huckleberry Finn" [J]. Chinese School Education, 2009(S1): 10-10.

[8] Zhang Li, Gao Yunyan. The Cultural Interpretation of Colonialism after The Adventures of Huckleberry Finn[J]. Xijiang Yue, 2010(4):56-58. 